Original Research Article

\title{
Molecular Docking Studies of Phytoconstituents Identified in Traditional Siddha Polyherbal Formulations Against Possible Targets of SARS-CoV-2
}

\section{Logesh Kumar Selvaraj ${ }^{1}$}

Geethanjali Thayumanavan 1

Srikanth Jeyabalan ${ }^{*} *$

Sugin Lal Jabaris 2

1Department of Pharmacology, Sri Ramachandra Faculty of Pharmacy, Sri Ramachandra Institute of Higher Education and Research, Chennai, Tamil Nadu, India

2Department of Pharmacology, Siddha Central Research Institute, Central Council for Research in Siddha, Chennai, Tamil Nadu, India

*email:

srikanth.j@sriramachandra.edu.in

Keywords:

ACE2

ADME

Molecular docking

Phytochemicals

Spike protein

\begin{abstract}
The Indian Traditional Medicines System has long used Siddha polyherbal formulations for different viral diseases. The ingredients of these formulas have been proven to be antiviral. The study focuses on in silico computational evaluation of phytoconstituents of the official Siddha formulation Kabasura, Thonthasura, and Vishasura Kudineer, which were widely used in treating viral fever and respiratory infections and may influence the current SARS-CoV-2 coronary virus pandemic. Maestro interface (Schrödinger Suite, LLC, NY) was used for molecular docking studies against $\mathrm{M}^{\text {Pro }}$ (PDB ID 5R82, 6Y2F, and 6LU7), Nsp15 endoribonuclease (6W01), RNA-dependent RNA polymerase (6M71), and spike protein (6VW1) of SARS-CoV-2. In addition, pharmacokinetics (ADME) and safety profile prediction studies were performed to identify the best drug candidates using Qikpro and Toxicity Estimation Software Tool (T.E.S.T). A total of 36 compounds were screened, of which nine displayed strong binding affinity and drug-likeness. Luteolin and chrysoeriol produced stronger results. These nine compounds were free of oral toxicity as evaluated by the Toxicity estimation software. Based on further in vitro, in vivo, and clinical effectiveness trials, these compounds may be used for the prevention or treatment as per the Indian system of traditional medicines.
\end{abstract}

Received: May 2nd, 2021

Accepted: June 7th, 2021

Published: June 30th, 2021

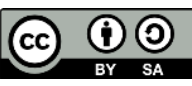

(c) 2021 Logesh Kumar Selvaraj, Geethanjali Thayumanavan, Srikanth Jeyabalan, Sugin Lal Jabaris. Published by Institute for Research and Community Services Universitas Muhammadiyah Palangkaraya. This is an Open Access article under the CC-BY-SA License (http://creativecommons.org/licenses/by-sa/4.0/). DOI: https:// doi.org/10.33084/jmd.v1i1.2264

\section{INTRODUCTION}

Ever since the outbreak of COVID-19 caused by Severe acute respiratory syndrome coronavirus 2 (SARSCoV-2) in Wuhan, China, the world has witnessed the rapid spread of the pandemic across the world 1 . World Health Organization (WHO) reported approximately $82,579,768$ COVID-19 cases and 1,818,849 deaths as of January 2nd, 2021, with cases reported in more than 222 countries/territories. This novel coronavirus outbreak has posed a severe burden to the global economic, medical, and public health infrastructure ${ }^{2}$.

The COVID-19 is primarily a droplet-spread infection, and patients exhibit various symptoms of which fever, dry cough, and fatigue are predominant ${ }^{3}$. In some cases, the symptoms had rapidly developed to acute respiratory distress syndrome, metabolic acidosis, septic shock, coagulation dysfunction, eventually leading to multiple organ failure ${ }^{4-6}$. However, mild or asymptomatic COVID-19 patients can recover shortly after isolation and healthy lifestyle and food habits?. There is no particular treatment available for COVID19 infection except for comprehensive support by the combination of broad-spectrum antibiotics, antiviral and anti-malarial drugs, corticosteroids, and convalescent plasma therapy ${ }^{8}$. Numerous clinical trials are in progress, including identifying vaccines against SARS-CoV-2. Researchers and health care professionals are in desperate search of an effective 
cure for this pandemic. In the current scenario where the conventional drugs do not prove to be much efficacious, exploring the traditional system of medicine could be a feasible and hopeful strategy ${ }^{9}$. Traditional, complementary, and alternative medicine has a long history of providing primary beneficial health care to the population ${ }^{10}$.

India has an unmatched alternative system of medicine in the form of Ayurveda, Yoga, and Naturopathy, Unani, Siddha, Homeopathy, which is now jointly referred to as Ayush, recognized by the Government of India ${ }^{11}$. Siddha Medicine is one of India's oldest (5000 years old) and well-documented medical systems and is practiced mainly in South India, especially in Tamil Nadu and Sri Lanka, Malaysia, Singapore, and Mauritius, where Tamils $\operatorname{live}^{12}$. In the current pandemic situation, many strategies would be highly critical to combat the rapid virus spread and treat the infection. Ministry of Ayush, Government of India has issued an "Advisory on Coronavirus" to manage this outbreak and broadly comprises of preventive and prophylactic symptom management of COVID-19 like illnesses and also insights to interventions based on Ayush systems of medicine through the evidence for immunity boosting as well as help in improving the respiratory symptoms ${ }^{13}$.

Drug discovery and development involve a long time, a vast number of individuals, high prices. In silico screening approaches allow researchers to explore new and potentially active lead compounds in less time, expense, and humans ${ }^{14}$. Siddha polyherbal formulations are potent against several causative agents such as influenza, chikungunya, dengue, tuberculosis, and others ${ }^{15-17}$. Siddha medicines have been used successfully by Siddha practitioners and ordinary citizens for the treatment of many diseases for several years, such as Kabasura Kudineer during influenza outbreaks, Nilavembu Kashayam for dengue fever. Kabasura kudineer, Thonthasura kudineer, and Vishasura kudineer are polyherbal formulations that have long been used in Siddha medication for different health problems, including currently being developed for COVID-19 therapy ${ }^{18-19}$. These polyherbal formulas are made up of different medicinal plants.

This study aims to evaluate the activity of phytoconstituents in Siddha polyherbal formulations against various potential SARS-CoV-2 targets using in silico methods. Thirty-six phytoconstituents were selected from these medicinal plants and docked against all potential SARS-CoV-2 targets, including $\mathrm{M}^{\text {Pro, }}$ Nsp15 endoribonuclease, RNA-dependent RNA polymerase (RdRp), and spike protein, utilizing Maestro 11.8 (Schrodinger 2018-4 package).

\section{METHOD}

\section{Hardware and Software}

Software used includes Maestro 11.8 from Schrödinger, Inc (https://www.schrodinger.com/products/maestro) and Toxicity Estimation Software Tool (T.E.S.T.) 4.2.1 from United States Environmental Protection Agency (https://www.epa.gov/chemical-research/toxicityestimation-software-tool-test).

\section{Ligands}

Hygrophila auriculata, Piper longum, Syzygium aromaticum, Tragia involucrata, Clerodendrum serratum, Anacyclus pyrethrum, Terminalia chebula, Adhatoda vasica, Coleus amboinicus, Saussurea lappa, Tinospora cordifolia, Andrographis paniculata, Sida acuta, Cyperus rotundus, and Zingiber officinale were the 15 ingredients of Kabasura Kudineer ${ }^{20,21}$. The Thonthasura Kudineer contains ten ingredients, including Z. officinale, $A$. vasica, A. paniculata, T. cordifolia, Elettaria cardamomum, Solanum xanthocarpum, Trichosanthes cucumerina, Tephrosia purpurea, Mollugo cerviana, and Vitis vinifera22. While the Vishasura Kudineer consists of nine ingredients, including Azadirachta indica, Z. officinale, Hemidesmus indicus, Indigofera tinctoria, Aristolochia bracteolata, E. cardamomum, Vetiveria zizanioides, Santalum album, and Glycyrrhiza glabra ${ }^{23}$.

The major active phytoconstituents present in those plants were selected. The selected 36 phytoconstituents including $\beta$-sesquiphellandrene (PubChem ID 11106487), $\beta$-bisabolene (10104370), geranial/citral (638011), piperine (638024), piperlonguminine (5320621), eugenol (3314), $\beta$ caryophyllene (5281515), stigmasterol (5280794), squalene (638072), $\gamma$-sitosterol/clionasterol (457801), andrograpanin (11666871), moslosooflavone/5hydroxy-7,8-dimethoxyflavone (188316), lupeol (259846), betulin (72326), chebulagic acid (442674), gallic acid (370), vasicinone (10242), carvacrol (10364), cirsimaritin (188323), chrysoeriol (5280666), luteolin (5280445), costunolide (5281437), elemol (92138), tinosponone (15215479), bharangin (194464), 
scutellarein (5281697), magnoflorine (73337), cycleanine (121313), cyperene (99856), $\beta$-selinene (442393), zingiberene (92776), vasicine (442929), cucurbitacin B (5281316), andrographolide (5318517), apigenin (5280443), pyrethrin I (5281045), and the reference drugs (chloroquine, hydroxychloroquine, ivermectin, lopinavir, remdesivir, and ritonavir) were downloaded from the PubChem database (https://pubchem.ncbi.nlm.nih.gov/).

\section{Receptors}

All potential SARS-CoV-2 targets, including $\mathrm{M}^{\text {Pro, }}$ Nsp15 endoribonuclease, RdRp, and spike protein, have been selected to evaluate the optimum ligand. The 3D structure of selected proteins has been downloaded from Protein Data Bank (https://www.rcsb.org). The PDB ID of the selected proteins was $\mathrm{M}^{\text {Pro }}$ (5R82, 6Y2F, 6LU7), Nsp15 endoribonuclease (6W01), $\operatorname{RdRp}(6 \mathrm{M} 71)$, and spike protein $(6 \mathrm{VW} 1)^{24-29}$.

\section{Docking protocol}

Preparation of ligands

The ligand minimization was carried out by the LigPrep module in Maestro 11.8. The 3D ligand structure was generated, and hydrogen atoms were introduced. Salt reduction and ionization ( $\mathrm{pH} 7.0 \pm 2.0)$ were conducted, and the minimization was performed utilizing the OPLS-2005 force field ${ }^{30,31}$.

\section{Preparation of protein}

Protein Preparation Wizard was used to prepare protein structures. Bond orders were assigned, and hydrogen atoms were inserted. Within $3 \AA$ of the het groups, the water molecules were removed, and the missing side chains were filled with prime. As a result, hydrogen bonds (H-bond) were optimized and reduced using the OPLS 2005 force field. The cocrystallized ligand binding sites have been identified after elimination. The receptor grid was then created using the "Glide's Receptor Grid Generation" module with a $20 \AA$ A radius ${ }^{30,31}$.

\section{Molecular docking and free energy calculation}

The molecular docking between receptor binding sites and ligands was conducted using the Glide Module of Maestro 11.8, and the lowest binding pose of each ligand was maintained. Glide docking scores were performed in three high-throughput virtual screening (HTVS), standard precision (SP), and extra precision (XP) modes. Firstly, docking was performed with reference molecules of respective proteins to validate the docking protocol. We used the XP mode for docking. After XP mode docking, compounds were sent to Prime MMGBSA from Maestro 11.8 for free energy calculations.

\section{$A D M E$ and toxicity analysis}

Out of the 36 compounds, ten compounds were chosen based on the docking performance. The chosen compounds were used in the ADME study using the QikProp module from Maestro 11.8, and the following parameters were determined.

1. The molecular weight of the molecule.

2. Predicted octanol/water partition coefficient.

3. Predicted brain/blood partition coefficient.

4. Percent human-oral absorption

5. Lipinski's rule of five.
a. mol_MW $<500$
b. $\mathrm{QP} \log \mathrm{Po} / \mathrm{w}<5$
c. donorHB $\leq 5$
d. $\operatorname{accptHB} \leq 10$

6. Jorgensen's rule of three
a. QPlogS >-5.7
b. QP PCaco $>22 \mathrm{~nm} / \mathrm{s}$
c. \# Primary Metabolites $<7$

Toxicity was measured using T.E.S.T. 4.2.1. Oral rats $\mathrm{LD}_{50}$, developmental toxicity, and Ames mutagenicity were conducted using four methods: Consensus system, Hierarchical clustering method, FDA method, and Nearest neighbor method ${ }^{32}$.

1. Hierarchical method $[\mathrm{HM}]$ : Using the weighted average of estimates from several separate models, the toxicity of a specified question compound was determined. Using the Ward approach to fragment the training set into a sequence of structurally linked clusters, the separate models were obtained. A genetic algorithm-based approach was used to create models for each cluster. Models were created before runtime.

2. FDA Method [FM]: For and test product, the prediction was produced using a new model appropriate for chemicals closest to the test compound. Each model was generated at runtime.

3. Nearest neighbor method [NM]: The predicted toxicity was calculated by taking an average of the three chemicals most comparable to the research chemicals in the training kit. 
4. Consensus Method [CM]: The predicted toxicity was calculated by taking an average of the predicted toxicity from the QSAR as mentioned earlier methods (provided the predictions were within the respective applicability domains).

\section{RESULTS AND DISCUSSION}

\section{Molecular docking and free energy calculation}

Compounds with a docking score of less than -6.0 were deemed possible candidates against SARS-CoV2, as represented in Table I for a comparative study. Out of 36 molecules, luteolin, chrysoeriol, and cucurbitacin B have been associated with more than two receptor structures. Luteolin displays a docking score less than -6 with $\mathrm{M}^{\mathrm{Pro}}$, Nsp15 endoribonuclease, and RdRp, as seen in Figure 1.

Table I. Comparative docking analysis of ligands against $\mathrm{M}^{\text {Pro, }}$ Nsp15 endoribonuclease, RdRp, and spike protein

\begin{tabular}{|c|c|c|c|c|c|c|}
\hline \multirow{2}{*}{ Compounds } & \multicolumn{6}{|c|}{ Receptors (PDB ID) } \\
\hline & $5 \mathbf{R} 82$ & $6 \mathrm{Y} 2 \mathrm{~F}$ & 6LU7 & $6 \mathrm{~W} 01$ & 6 M71 & $6 \mathrm{VW1}$ \\
\hline Remdesivir & -5.478 & -5.306 & -7.189 & -7.829 & -8.643 & -7.206 \\
\hline Hydroxychloroquine & -5.395 & -2.741 & -4.438 & -4.814 & -4.177 & -8.748 \\
\hline Chloroquine & -4.203 & -1.587 & -3.98 & -5.896 & -2.191 & N/A ${ }^{*}$ \\
\hline Lopinavir & -5.373 & -3.5 & -4.535 & -5.953 & -7.797 & -6.702 \\
\hline Ritonavir & -3.927 & -5.233 & -6.79 & -5.848 & -1.198 & -6.493 \\
\hline Ivermectin & -3.037 & -3.427 & -4.44 & -4.187 & -3.558 & N/A \\
\hline Luteolin & -7.408 & -6.036 & -7.47 & -7.314 & -6.304 & N/A \\
\hline Scutellarein & -6.807 & -6.081 & -7.587 & -7.191 & N/A & N/A \\
\hline Chrysoeriol & -6.473 & -6.394 & -7.342 & -6.43 & -6.174 & N/A \\
\hline Cucurbitacin B & -6.267 & N/A & -6.946 & -7.021 & -6.488 & N/A \\
\hline Apigenin & -6.065 & N/A & -6.22 & -6.41 & N/A & N/A \\
\hline Andrographolide & -6.042 & N/A & N/A & N/A & N/A & N/A \\
\hline Cirsimaritin & -6.031 & N/A & -6.743 & -6.461 & N/A & N/A \\
\hline Moslosooflavone & -6.003 & N/A & -6.973 & N/A & N/A & N/A \\
\hline Gallic acid & N/A & N/A & N/A & -6.379 & $\mathrm{~N} / \mathrm{A}$ & N/A \\
\hline Pyrethrin & N/A & N/A & N/A & N/A & -6.704 & N/A \\
\hline Cycleanine & $\mathrm{N} / \mathrm{A}$ & $\mathrm{N} / \mathrm{A}$ & N/A & $\mathrm{N} / \mathrm{A}$ & $\mathrm{N} / \mathrm{A}$ & -6.907 \\
\hline
\end{tabular}

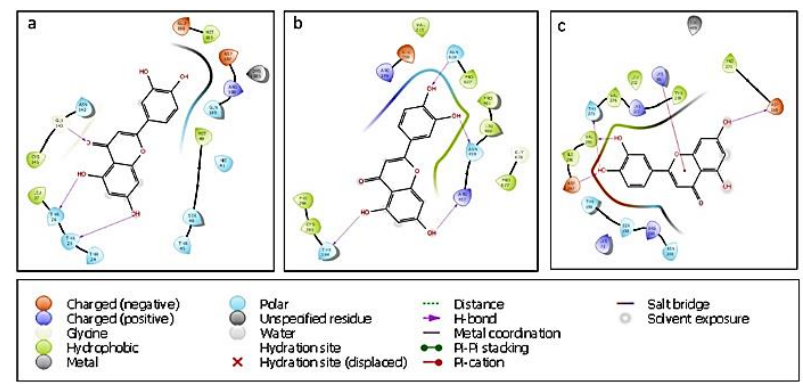

Figure 1. Binding-interaction analysis of luteolin with (a) $\mathrm{M}^{\text {Pro, }}$ with (b) RdRp, and with (c) Nsp15 endoribonuclease.

Chrysoeriol also displays a docking score less than -6.0 with $\mathrm{M}^{\text {Pro, }}$ Nsp15 endoribonuclease, and RdRp, as seen in Figure 2. The associations of luteolin and chrysoeriol with various SARS-CoV-2 target forms were comparatively analyzed, in which H-bond and hydrophobic pockets were presented in Tables II and III. Luteolin shows hydrogen bonding with nearly four amino acids of most of the targets. This finding shows its high binding potency towards the SARSCoV-2.

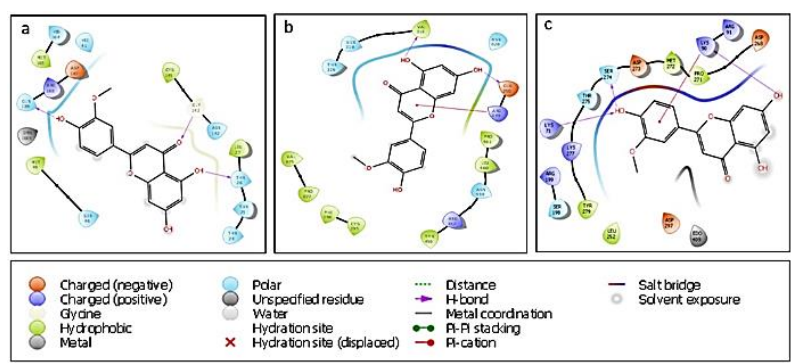

Figure 2. Binding-interaction analysis of chrysoeriol with (a) $\mathrm{M}^{\text {Pro, }}$ with (b) RdRp, and with (c) Nsp15 endoribonuclease.

Table II. Binding interactions of luteolin with the active sites of different targets in SARS-CoV-2

\begin{tabular}{lcll}
\hline \multicolumn{1}{c}{ Target } & $\begin{array}{c}\text { PDB } \\
\text { ID }\end{array}$ & H-Bond & Hydrophobic pocket \\
\hline M Pro $^{\text {PR82 }}$ & GLY 143, & CYS 145, MET 165, \\
& & THR 26, & MET 49, LEU 27 \\
& & THR 25 & \\
& 6LU7 & THR 26 & LEU 27, CYS 145, \\
& & & CYS 44, MET 49, PRO \\
& \multirow{2}{*}{ 6Y2F } & GLU 166, & LEU 27, VAL 42, CYS \\
& & LEU 141, & 44, TYR 54, MET 49, \\
& & HIE 163, & PHE 140, LEU 141, \\
& & HIE 41 & LYS 145, MET 165 \\
RdRp & 6M71 & THR 394, & PHE 396, CYS 395, \\
& & ARG 457, & VAL 315, PRO 627, \\
& & ASN 628, & PRO 461, LEU 460, \\
Nsp15 & 6WN 459 & PRO 677 \\
endoribo- & & ASP 268, & PRO 271, LEU 252, \\
nuclease & & ASP 297, & VAL 295, ILE 296, \\
& & THR 275, & VAL 276, TYR 279 \\
\hline
\end{tabular}

Table III. Binding interactions of chrysoeriol with the active sites of different targets in SARS-CoV-2

\begin{tabular}{|c|c|c|c|}
\hline Target & $\begin{array}{l}\text { PDB } \\
\text { ID }\end{array}$ & H-Bond & Hydrophobic pocket \\
\hline \multirow[t]{3}{*}{$\mathrm{M}^{\text {Pro }}$} & $5 \mathrm{R} 82$ & $\begin{array}{l}\text { GLN 189, } \\
\text { GLY 143, } \\
\text { THR 26 }\end{array}$ & $\begin{array}{l}\text { CYS 145, LEU 27, } \\
\text { MET 49, MET } 165\end{array}$ \\
\hline & 6LU7 & THR 26 & $\begin{array}{l}\text { CYS 44, PRO 52, MET } \\
49, \text { TYR 54, MET 165, } \\
\text { CYS } 145, \text { LEU } 27\end{array}$ \\
\hline & $6 \mathrm{Y} 2 \mathrm{~F}$ & $\begin{array}{l}\text { ASP 187, } \\
\text { GLU 166, } \\
\text { LEU } 141\end{array}$ & $\begin{array}{l}\text { CYS } 44, \text { LEU } 141 \text {, } \\
\text { CYS } 145, \text { MET } 165, \\
\text { TYR } 54, \text { MET } 49\end{array}$ \\
\hline $\operatorname{RdRp}$ & $6 \mathrm{M} 71$ & $\begin{array}{l}\text { VAL } 315, \\
\text { GLU } 350\end{array}$ & $\begin{array}{l}\text { VAL 315, PRO 461, } \\
\text { LEU 460, PHE 396, } \\
\text { CYS 395, TYR 456, } \\
\text { PRO 677, VAL } 675\end{array}$ \\
\hline $\begin{array}{l}\text { Nsp15 } \\
\text { endoribo- } \\
\text { nuclease }\end{array}$ & 6W01 & $\begin{array}{l}\text { LYS 71, } \\
\text { SER 275, } \\
\text { LYS } 90\end{array}$ & $\begin{array}{l}\text { TYR 279, MET 272, } \\
\text { PRO 271, LEU } 252\end{array}$ \\
\hline
\end{tabular}


In the molecular docking of phytoconstituents with $\mathrm{M}^{\text {Pro }}$ (5R82), luteolin had a higher affinity with a docking score of -7.408 , followed by scutellarein and chrysoeriol with docking scores of -6.807 and -6.473 , respectively. These phytoconstituents had a higher affinity to $\mathrm{M}^{\text {Pro }}$ (5R82) than remdesivir, displaying a docking score of -5.478 . Chrysoeriol had a higher affinity with a docking score of -6.394 , followed by scutellarein and luteolin with docking scores of -6.081 and -6.036 , respectively with the target $\mathrm{M}^{\text {Pro }}$ (6Y2F). These phytoconstituents had a higher affinity to $\mathrm{M}^{\mathrm{Pro}}$ (6Y2F) than remdesivir, with a docking score of -5.306. Scutellarein had a greater affinity with a docking score of -7.587 , followed by luteolin and chrysoeriol with 7.470 and -7.342 , respectively, for molecular docking of phytoconstituents with MPro (6LU7). These phytoconstituents had a higher affinity than remdesivir, which had a docking score of -7.189.

Remdesivir shows greater affinity with a docking score of -7.829 , followed by scutellarein and cucurbitacin B with a score of -7.314 and -7.191, respectively, in the docking analysis with Nsp15 endoribonuclease (6W01). With RdRp (6M71), remdesivir had a higher affinity with a docking score of -8.643 , followed by pyrethrin and cucurbitacin B with docking scores -6.704 and -6.488 , respectively. Hydroxychloroquine had a higher affinity with a docking score of -8.748 , followed by remdesivir and cycleanine, which had a docking score of -7.206 and 6.907, respectively, with the target spike protein (6VW1). Most phytoconstituents exhibited similar reference drugs in binding energies and binding pockets, except gallic acid, pyrethrin, chebulagic acid, and cycleanine.

Chrysoeriol shows less hydrogen bonding than the luteolin but better than other phytoconstituents. The hydrogen bonding of both luteolin and chrysoeriol could be increased by substitute better chemical groups. The prime MM-GBSA was generally accepted for the re-scoring of docked complexes. Both of the chosen complexes were subjected to prime MM-GBSA measurements after XP Docking33. MM-GBSA DGbind scores for all chosen compounds were displayed in Table IV. The negative DG-bind values indicate that the selected compounds associate favorably with the receptor. Ligand binding energies for both substances vary from -40.0 to $-100.0 \mathrm{kcal} / \mathrm{mol}$. The binding energies of several of the substances were relatively close to those of the reference drug binding energy. These findings indicate that the selected compounds would inhibit SARS-CoV-2.

Table IV. MM-GBSA DG-bind values of selected compounds

\begin{tabular}{lllllll}
\hline \multirow{2}{*}{ Compounds } & \multicolumn{6}{c}{ Receptors (PDB ID) (kcal/mol) } \\
\cline { 2 - 7 } & 5R82 & 6Y2F & 6LU7 & 6W01 & 6M71 & 6VW1 \\
\hline Remdesivir & -63.6 & -74.01 & -79.74 & -61.48 & -73.53 & -47.55 \\
Hydroxychloroquine & -77.77 & -94.09 & -64.02 & -46.21 & N/A* & -64.72 \\
Chloroquine & -62.03 & -87.32 & -78.62 & -36.65 & N/A & -66.13 \\
Lopinavir & -59.92 & -52.27 & -48.39 & -47.87 & -93.51 & -70.62 \\
Ritonavir & -93.22 & -88.95 & -96.23 & -69.29 & N/A & -31.95 \\
Ivermectin & -62.33 & -59.89 & -55.15 & -66.39 & N/A & -54.7 \\
Luteolin & -45.23 & -26.87 & -54.84 & -41.3 & -48.75 & N/A \\
Scutellarein & -43.21 & -41.37 & -50.83 & -44.21 & N/A & N/A \\
Chrysoeriol & -56.63 & -23.2 & -56.63 & -39.5 & -54.83 & N/A \\
Cucurbitacin B & -82.11 & N/A & -63.88 & -58.96 & -79.78 & N/A \\
Apigenin & -45.79 & N/A & -52.44 & -43.85 & N/A & N/A \\
Andrographolide & -69.79 & N/A & -51.5 & N/A & N/A & N/A \\
Cirsimaritin & -53.92 & N/A & -55.73 & -50.21 & N/A & N/A \\
Moslosooflavone & -51.89 & N/A & -56.77 & N/A & N/A & N/A \\
Gallic acid & N/A & N/A & N/A & -18.15 & N/A & N/A \\
Pyrethrin & N/A & N/A & N/A & N/A & -79.94 & N/A \\
Cycleanine & -63.6 & -74.01 & -79.74 & -61.48 & -73.53 & -47.55 \\
\hline *N/A: Not available & \multicolumn{7}{c}{} &
\end{tabular}

\section{ADME analysis}

The absorption, distribution, metabolism, and elimination of substances play an essential role in the drug development phase. In silico ADME analysis would save thousands of dollars spent in the drug development phase by producing fewer new compounds ${ }^{34}$. The ADME parameters, such as mol MW, QPlogPo/w, QPlogBB, percent human oral absorption, Rule of Five, and Rule of Three using QikProp showed a better score for the docked compounds ${ }^{35}$. Both of the chosen nine compounds have enhanced ADME properties and drug-likeness according to the spectrum as shown in Table V. All of the nine phytoconstituents have enhanced ADME properties. Cucurbitacin B violates a rule of 1 of 5 , which was appropriate. Gallic acid and pyrethrin were in breach of a law of three that was fitting. Luteolin and chrysoeriol display improved drug-likeness and high binding capacity, all of which were essential to the drug candidate.

Table V. ADME prediction for the selected compound

\begin{tabular}{|c|c|c|c|c|c|c|}
\hline 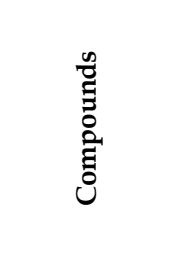 & $\frac{\sum}{\sum}$ & $\begin{array}{l}\frac{\infty}{00} \\
\frac{0}{00} \\
\frac{0}{a}\end{array}$ & $\begin{array}{l}3 \\
0 \\
0 \\
0 \\
0 \\
\overline{0}\end{array}$ & 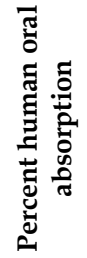 & 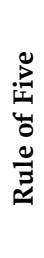 & 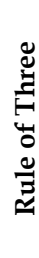 \\
\hline Andrographolide & 350.454 & -1.222 & 1.437 & 79.068 & 0 & 0 \\
\hline Apigenin & 270.241 & -1.411 & 1.624 & 73.955 & 0 & 0 \\
\hline Chrysoeriol & 300.267 & -1.409 & 1.81 & 76.672 & 0 & 0 \\
\hline Cucurbitacin B & 558.711 & -1.964 & 2.92 & 67.293 & 1 & 0 \\
\hline Gallic acid & 170.121 & -1.659 & -0.585 & 41.441 & 0 & 1 \\
\hline Luteolin & 286.24 & -1.91 & 0.941 & 62.05 & 0 & 0 \\
\hline Pyrethrin & 372.46 & -1.157 & 4.385 & 100 & 0 & 1 \\
\hline Scutellarein & 286.24 & -1.819 & 1.001 & 63.924 & 0 & 0 \\
\hline Moslosooflavone & 298.295 & -0.43 & 3.165 & 100 & 0 & 0 \\
\hline
\end{tabular}




\section{In silico toxicity study}

The oral rat $L D_{50}$

The endpoint of the oral rat $L D_{50}$ was the amount of the chemical (chemical mass per rat body weight) that destroys half of the rats when administered orally ${ }^{36}$. The oral rat $\mathrm{LD}_{50}$ was conducted in four methods for all of the chosen compounds, and the findings were comparatively evaluated in Table VI. All substances have been shown to have an acceptable toxicity limit for drug production and preclinical and clinical assessment.

\section{Developmental toxicity}

Developmental toxicity includes embryonic and fetal mortality, miscarriage, and other abnormal developmental symptoms such as liver toxicity, lowered body weight, growth, developmental retardation, and physical abnormalities (teratogenic effects) ${ }^{37}$. Developmental toxicity was performed in four approaches with all of the chosen compounds, and the findings were comparatively analyzed in Table VI. A predicted value greater than 0.5 indicates toxicity. Except gallic acid, all other compounds show developmental toxicity.

\section{Ames mutagenicity}

In Ames assay, frame-shift mutations or base-pair substitutions could be identified by exposure of histidine-dependent strains of Salmonella typhimurium to the test compound. When these strains were exposed to a mutagen, reversing mutations that restore the functional capacity of the bacteria to synthesize histidine would cause the bacterial colony to develop on a medium histidine deficiency (revertant) ${ }^{38}$.

A compound was labeled Ames positive if it significantly induces the development of the reverting colony in at least one of the five strains. If a compound was positive for the Ames test, it could be a possible mutagen ${ }^{39}$. Ames mutagenicity was conducted in four methods for all of the chosen compounds, and the findings were comparatively analyzed in Table VI. A predicted value greater than 0.5 indicates mutagenicity. All the nine phytoconstituents except pyrethrin were not mutagens based on the results on the Ames mutagenicity as predicted by T.E.S.T software.
Table VI. Predicted value for oral rat $\mathrm{LD}_{50}-\log ^{10}(\mathrm{~mol} / \mathrm{kg})$, developmental toxicity, and Ames mutagenicity

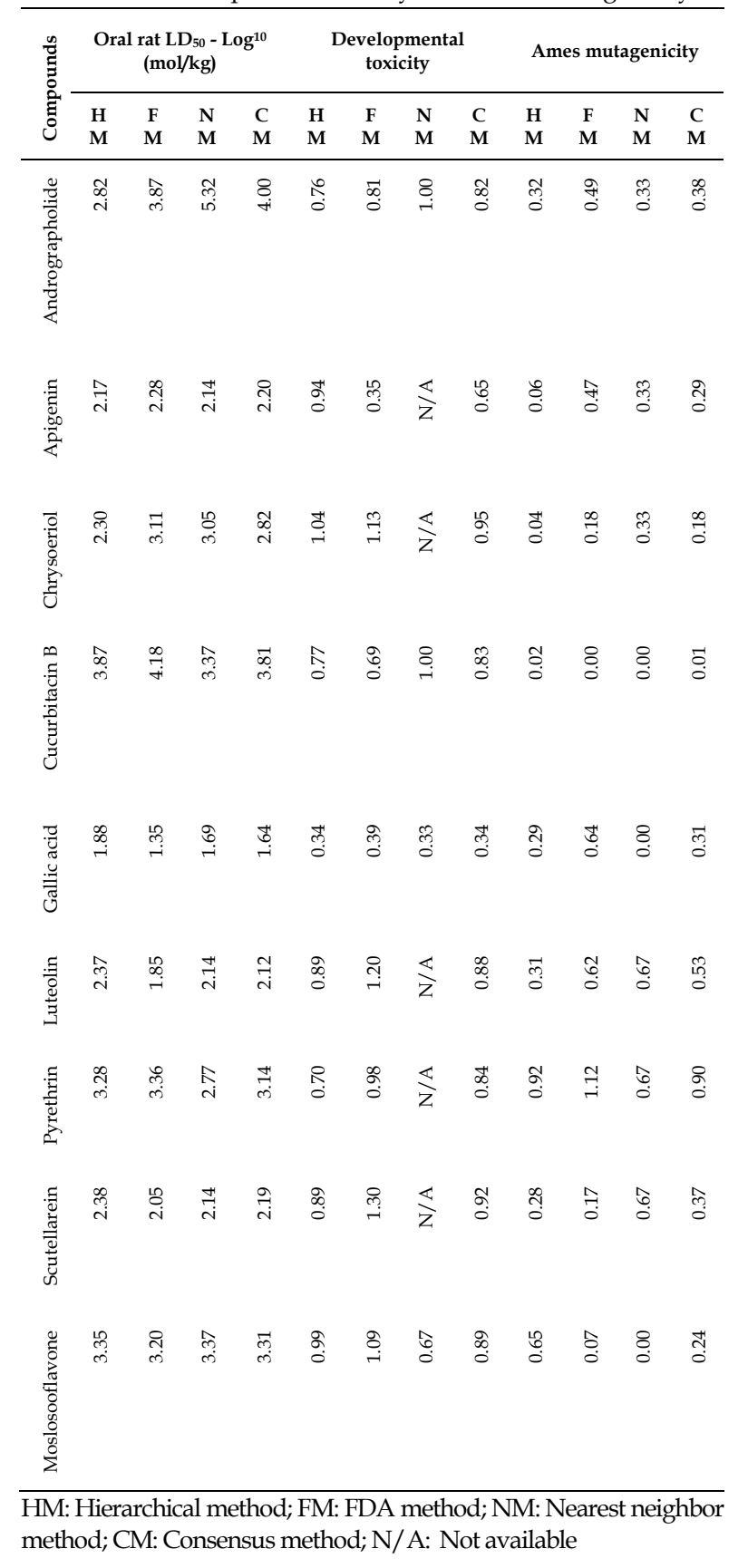

Our current research has chosen three Official Siddha Formulation Kabasura, Thonthasura, and Vishasura Kudineer to test its potential against SARS-CoV-2 targets. Siddha medicine is one of the oldest Indian systems of medicine. The methods of Siddha emerged in India, and it was most commonly practiced in India, especially in southern regions. Siddha medicinal plants were a promising area for the treatment of a wide variety of diseases. Siddha medicinal plants might also be considered a new choice for their role in overcoming viral transmission ${ }^{40,41}$. 
Mekala and Krishnamurthy ${ }^{42}$ performed the phytochemical screening and pharmacological update on Kabasura Kudineer Choornam and Nilavembu Kudineer Choornam. Kabasura Kudineer was found to have alkaloids, carbohydrates, glycosides, heartglycosides, flavonoids, phenols, saponins, and hydrolyzable present in Kabasura Kudineer Choornam. In addition to the broad range of other pharmacological operations, the ingredients in Kabasura Kudineer show that most of the components were antipyretic, anti-inflammatory, antimicrobial, and immunostimulant ${ }^{43}$. Therefore, it was scientifically rational to use it in respiratory viral infection.

The molecular docking study of Thonthasura Kudineer ingredients demonstrated affinity with the Coronavirus Spike (S) glycoprotein, carried out by Kumar et a ${ }^{22}$. Vishasura Kudineer was a polyherbal formulation from the Siddha literature 'Kaaviya Sura Nool'. Vishasura Kudineer was traditionally used for symptoms associated with viral fever. Its portion demonstrates antiviral activity against a wide variety of viruses. It might also be antipyretic, antiasthmatic, anti-inflammatory, antioxidant, hepatoprotective, and immunostimulant ${ }^{18}$.

Various research studies have been performed on different formulations of Siddha and its phytoconstituents against selective targets for SARSCoV-219,22,44. The main protease ( $\mathrm{M}^{\mathrm{Pro}}, 3 \mathrm{CL}^{\mathrm{Pro}}$, Nsp5) proteolytically cleaves the overlapping pp1a and pplab polyproteins to functional proteins, crucial in viral replication. In the viral replication cycle, the $\mathrm{M}^{\mathrm{Pro}}$ acts as the primary enzyme. Its inhibition could thus interfere with the production of infectious virus particles and reduce disease symptoms ${ }^{45}$.

The SARS-CoV-2 spike protein mediates the binding of the virus to its receptor angiotensin-converting enzyme 2 (ACE2) and facilitates the integration of viral and host cell membranes and the entrance of the virus into the host cell. Thus, the Spike protein was vital in neutralizing and T-cell reactions and maintaining immunity during SARS-CoV-2 infection. Given the essential role of the S-protein in viral infection and adaptive immunity, most methods and therapies were based on the S-protein ${ }^{46}$. RNA-dependent RNA Polymerase was an enzyme that replicates RNA from an RNA template. RNA-dependent RNA Polymerase was one of the Nsp (Nsp12) that plays a key role in the coronavirus life cycle ${ }^{47}$.
Nsp15 was responsible for protein interaction with the innate immune response, although other studies suggest that the mechanism was independent of endonuclease activity. In order to conceal it from the host's immune system, there were also reports that Nsp15 degrades viral RNA ${ }^{48}$. Nevertheless, in coronavirus biology, Nsp15 was important. The active site, located in a shallow groove between the two $\beta$ sheets, carries six key residues conserved among SARS-CoV-2, SARS-CoV, and MERS-CoV proteins: His235, His250, Lys290, Thr341, Tyr343, and Ser29427.

\section{CONCLUSION}

The present research was planned to classify potential drug candidates exhibiting potential binding affinity to all possible SARS-CoV-2 targets ( $\mathrm{M}^{\mathrm{Pro}}$, Nsp15 endoribonuclease, $\mathrm{RdRp}$, and spike protein). Based on the findings obtained from molecular docking, free energy measurement, ADME analysis, as well as toxicity analysis, luteolin and chrysoeriol exhibit stronger docking score, binding energy, ADME properties, and lower toxicity than all other compounds.

\section{CONFLICTS OF INTEREST}

There are no conflicts of interest to declare.

\section{FUNDING}

None.

\section{DATA AVAILABILITY}

All data are available from the authors.

\section{ACKNOWLEDGMENTS}

The authors thank Sri Ramachandra Institute of Higher Education and Research (Deemed University) management for providing us with all the facilities for completing the project.

\section{AUTHORS' CONTRIBUTIONS}

Logesh Kumar Selvaraj: conceptualization, data curation, formal analysis, investigation, methodology, project administration, software, visualization, writing - original draft. Geethanjali Thayumanavan: data curation, investigation, writing - original draft. Srikanth Jeyabalan: conceptualization, investigation, 
project administration, software, supervision, validation, writing - review \& editing. Sugin Lal Jabaris: supervision, validation, writing - review \& editing.

\section{REFERENCES}

1. Singhai T. A Review of Coronavirus Disease-2019 (COVID-19). Indian J Pediatr. 2020;87(4):281-6. doi:10.1007/s12098-020-03263-6

2. Kaye AD, Okeagu CN, Pham AD, Silva RA, Hurley JJ, Arron BL, et al. Economic impact of COVID-19 pandemic on healthcare facilities and systems: International perspectives. Best Pract Res Clin Anaesthesiol. 2020:[Epub ahead of print]. doi:10.1016/j.bpa.2020.11.009

3. Chen B, Liu M, Huang C. Current diagnostic and therapeutic strategies for COVID-19. J Pharm Anal. 2021;11(2):129-37. doi:10.1016/j.jpha.2020.12.001

4. Zaim S, Chong JH, Sankaranarayanan V, Harky A. COVID-19 and Multiorgan Response. Curr Probl Cardiol. doi:10.1016/j.cpcardiol.2020.100618

5. Espinoza D, Rodriguez R, Kowalski A. 24 Hours: A Case of Multiorgan Failure Associated With COVID-19. Cureus. 2020;12(8):e10149. doi:10.7759/cureus.10149

6. Li N, Zhu L, Sun L, Shao G. The effects of novel coronavirus (SARS-CoV-2) infection on cardiovascular diseases and cardiopulmonary injuries. Stem Cell Res. 2021;51:102168. doi:10.1016/j.scr.2021.102168

7. Fernández-Quintela A, Milton-Laskibar I, Trepiana J, Gómez-Zorita S, Kajarabille N, Léniz A, et al. Key Aspects in Nutritional Management of COVID-19 Patients. J Clin Med. 2020;9(8):2589. doi:10.3390/jcm9082589

8. Wadaa-Allah A, Emhamed MS, Sadeq MA, Dahman NBH, Ullah I, Farrag NS, et al. Efficacy of the current investigational drugs for the treatment of COVID-19: a scoping review. Ann Med. 2021;53(1):318-34.

doi:10.1080/07853890.2021.1875500

9. Yang $Y$, Islam MS, Wang J, Li Y, Chen X. Traditional Chinese Medicine in the Treatment of Patients Infected with 2019-New Coronavirus (SARS-CoV-2): A Review and Perspective. Int J Biol Sci. 2020;16(10):1708-17. doi:10.7150/ijbs.45538
10. Park YL, Canaway R. Integrating Traditional and Complementary Medicine with National Healthcare Systems for Universal Health Coverage in Asia and the Western Pacific. Health Syst Reform. 2019;5(1):24-31. doi:10.1080/23288604.2018.1539058

11. Rudra S, Kalra A, Kumar A, Joe W. Utilization of alternative systems of medicine as health care services in India: Evidence on AYUSH care from NSS 2014. PLoS One. 2017;12(5):e0176916. doi:10.1371/journal.pone.0176916

12. Sen S, Chakraborty R. Revival, modernization and integration of Indian traditional herbal medicine in clinical practice: Importance, challenges and future. J Tradit Complement Med. 2017;7(2):234-44. doi:10.1016/j.jtcme.2016.05.006

13. Jabaris SL, Ananthalakshmi V. The current situation of COVID-19 in India. Brain Behav Immun Health. 2021;100200. doi:10.1016/j.bbih.2021.100200

14. Paul D, Sanap G, Shenoy S, Kalyane D, Kalia K, Tekade RK. Artificial intelligence in drug discovery and development. Drug Discov Today. 2021;26(1):80-93. doi:10.1016/j.drudis.2020.10.010

15. Jain J, Pai S, Sunil S. Standardization of in vitro assays to evaluate the activity of polyherbal siddha formulations against Chikungunya virus infection. Virusdisease. 2018;29(1):32-9. doi:10.1007/s13337018-0421-0

16. Jain J, Kumar A, Narayanan V, Ramaswamy RS, Sathiyarajeswaran P, Devi MSS, et al. Antiviral activity of ethanolic extract of Nilavembu Kudineer against dengue and chikungunya virus through in vitro evaluation. J Ayurveda Integr Med. 2020;11(3):329-35.

doi:10.1016/j.jaim.2018.05.006

17. Mahadevan H, Palraj V. Literature Review on Siddha Herbal Formulations (Kudineer) Available for The Management of Dengue. Int J Pharmacol Clin Sci. 2016;5(3):90-6. doi:10.5530/ijpcs.5.3.5

18. Prakash P, Meena R, Stanley A, Swetha S, Govindaraju L, Durgasruthy P, et al. Evidencebased traditional Siddha formulations for prophylaxis and management of respiratory symptoms in COVID-19 pandemic- a review. Biocatal Agric Biotechnol. 2021:[Epub ahead of print]. doi:10.1016/j.bcab.2021.102056 
19. Kiran G, Karthik L, Devi MSS, Sathiyarajeswaran P, Kanakavalli K, Kumar KM, et al. In Silico computational screening of Kabasura Kudineer Official Siddha Formulation and JACOM against SARS-CoV-2 spike protein. J Ayurveda Integr Med. 2020:[Epub ahead of print]. doi:10.1016/j.jaim.2020.05.009

20. Ramalingam V, Venkataramani G. Unlocking the Potential of Traditional Native Medicines - A Perspective to Manage the COVID-19 Pandemic. J Res Trad Med. 2020;6(1):21-8. doi:10.5455/jrtm.2020/95807

21. Rajalakshmi P, Vadivel V, Sriram S, Brindha P. Evaluation of in vitro antioxidant and antiatherogenic properties of selected Siddha polyherbal decoctions. Int J Res Pharm Sci. 2020;11(2):1707-15. doi:10.26452/ijrps.v11i2.2072

22. Kumar PM, Sundaram KM, Ramasamy MS. Coronavirus spike (S) glycoprotein (2019-ncov) targeted siddha medicines kabasura kudineer and thonthasura kudineer -in silico evidence for corona viral drug. Asian J Pharm Res Health Care. 2020;12(1):20-7. doi:10.18311/ajprhc/2020/25103

23. Shailaja R, Sugunthan S, Kumar MP. A review on polyherbal formulation-Vishasura Kudineer chooranam-A classical anti-viral drug used in Siddha system of medicine. Eur J Pharm Med Res. 2017;4(9):184-92.

24. Douangamath A, Fearon D, Gehrtz P, Krojer T, Lukacik P, Owen CD, et al. Crystallographic and electrophilic fragment screening of the SARS-CoV2 main protease. Nat Commun. 2020:11(1):5047. doi:10.1038/s41467-020-18709-w

25. Zhang L, Lin D, Sun X, Curth U, Drosten C, Saurhering L, et al. Crystal structure of SARS-CoV2 main protease provides a basis for design of improved a-ketoamide inhibitors. Science. 2020;368(6489):409-12. doi:10.1126/science.abb3405

26. Jin Z, Du X, Xu Y, Deng Y, Liu M, Zhao Y, et al. Structure of $M$ pro from SARS-CoV-2 and discovery of its inhibitors. Nature. 2020;582(7811):289-93. doi:10.1038/s41586-0202223-y

27. Kim Y, Jedrzejczak R, Maltseva NI, Wilamowski M, Endres M, Godzik A, et al. Crystal structure of Nsp15 endoribonuclease NendoU from SARS-
CoV-2. Protein Sci. 2020;29(7):1596-605. doi:10.1002/pro.3873

28. Gao Y, Yan L, Huang Y, Liu F, Zhao Y, Cao L, et al. Structure of the RNA-dependent RNA polymerase from COVID-19 virus. Science. 2020;368(6492):77982. doi:10.1126/science.abb7498

29. Shang J, Ye G, Shi K, Wan Y, Luo C, Aihara H, et al. Structural basis of receptor recognition by SARSCoV-2. Nature. 2020;581(7807):221-4. doi:10.1038/s41586-020-2179-y

30. Sinha SK, Shakya A, Prasad SK, Singh S, Gurav NS, Prasad RS, et al. An in-silico evaluation of different Saikosaponins for their potency against SARSCoV-2 using NSP15 and fusion spike glycoprotein as targets. J Biomol Struct Dyn. 2020:1-12. doi:10.1080/07391102.2020.1762741

31. Shah B, Modi P, Sagar SR. In silico studies on therapeutic agents for COVID-19: Drug repurposing approach. Life Sci. 2020;252:117652. doi:10.1016/j.lfs.2020.117652

32. Ruiz P, Begluitti G, Tincher T, Wheeler J, Mumtaz M. Prediction of Acute Mammalian Toxicity Using QSAR Methods: A Case Study of Sulfur Mustard and Its Breakdown Products. Molecules. 2012;17(8):8982-9001. doi:10.3390/molecules17088982

33. Poli G, Granchi C, Rizzolio F, Tuccinardi T. Application of MM-PBSA Methods in Virtual Screening. Molecules. 2020;25(8):1971. doi:10.3390/molecules25081971

34. Lin J, Sahakian DC, de Morais SMF, Xu JJ, Polzer RJ, Winter SM. The role of absorption, distribution, metabolism, excretion and toxicity in drug discovery. Curr Top Med Chem. 2003;3(10):112554. doi:10.2174/1568026033452096

35. Divyashri G, Murthy TPK, Sundareshan S, Kamath P, Murahari M, Saraswathy GR, et al. In silico approach towards the identification of potential inhibitors from Curcuma amada Roxb against $\mathrm{H}$. pylori: ADMET screening and molecular docking studies. Bioimpacts. 2021;11(2):119-27. doi:10.34172/bi.2021.19

36. Chinedu E, Arome D, Ameh FS. A New Method for Determining Acute Toxicity in Animal Models. Toxicol Int, 2013;20(3):224-6. doi:10.4103/09716580.121674 
37. Kaleelullah RA, Garugula N. Teratogenic Genesis in Fetal Malformations. Cureus. 2021;13(2):e13149. doi:10.7759/cureus.13149

38. Levy DD, Hakura A, Elespuru RK, Escobar PA, Kato M, Lott J, et al. Demonstrating laboratory proficiency in bacterial mutagenicity assays for regulatory submission. Mutat Res Genet Toxicol Environ Mutagen. 2019;848:403075. doi:10.1016/j.mrgentox.2019.07.005

39. Wang WQ, Duan HX, Pei ZT, Xu RR, Qin ZT, Zhu GC, et al. Evaluation by the Ames Assay of the Mutagenicity of UV Filters Using Benzophenone and Benzophenone-1. Int J Environ Res Public Health. doi:10.3390/ijerph15091907

40. Balachandar V, Mahalaxmi I, Kaavya J, Vivekanandhan G, Ajithkumar S, Arul N, et al. COVID-19: emerging protective measures. Eur Rev Med Pharmacol Sci. 2020;24(6):3422-5. doi:10.26355/eurrev_202003_20713

41. Vellingiri B, Jayaramayya $K$, Iyer M, Narayanasamy A, Govindasamy V, Giridharan B, et al. Sci Total Environ. 2020;725:138277. doi:10.1016/j.scitotenv.2020.138277

42. Mekala P, Krishnamurthy TRG. Phytochemical screening and pharmacological update on Kabasura Kudineer Choornam and Nilavembu Kudineer Choornam P Mekala and TR Gopala Krishna Murthy. J Pharmacogn Phytochem. 2020;9(3):1031-6. doi:10.22271/phyto.2020.v9.i3q.11428

43. Ahmad S, Zahiruddin S, Parveen B, Basist P, Parveen A, Gaurav, et al. Indian Medicinal Plants and Formulations and Their Potential Against COVID-19-Preclinical and Clinical Research. Front Pharmacol. 2020;11:578970. doi:10.3389/fphar.2020.578970

44. Hall Jr DC, Ji HF. A search for medications to treat COVID-19 via in silico molecular docking models of the SARS-CoV-2 spike glycoprotein and 3CL protease. Travel Med Infect Dis. 2020;35:101646. doi:10.1016/j.tmaid.2020.101646

45. Ullrich S, Nitsche C. The SARS-CoV-2 main protease as drug target. Bioorg Med Chem Lett. 2020;30(17):127377. doi:10.1016/j.bmcl.2020.127377

46. Bian J, Li Z. Angiotensin-converting enzyme 2 (ACE2): SARS-CoV-2 receptor and RAS modulator. Acta Pharm Sin B. 2021;11(1):1-12. doi:10.1016/j.apsb.2020.10.006

47. Juang $Y$, Yin $W, X u$ HE. RNA-dependent RNA polymerase: Structure, mechanism, and drug discovery for COVID-19. Biochem Biophys Res Commun. 2021;538:47-53.

doi:10.1016/j.bbrc.2020.08.116

48. Rohaim MA, El Naggar RF, Clayton E, Munir M. Structural and functional insights into nonstructural proteins of coronaviruses. Microb Pathog. 2021;150:104641. doi:10.1016/j.micpath.2020.104641 